\title{
A GESTÃO PATRIMONIAL NA ADMINISTRAÇÃO PÚBLICA: UM ESTUDO DE CASO NO CIEP 293 - WALMIR DE FREITAS MONTEIRO
}

\author{
Renato Alencar de Moraes ${ }^{1}$
}

RESUMO: O intuito deste artigo é estudar o controle patrimonial dos bens na administração pública como um instrumento de Governança Pública. A Gestão Patrimonial voltada à administração pública tem por objetivo principal atender as demandas por materiais permanentes e de consumo com o intuito de viabilizar as diversas atividades desenvolvidas em uma determinada instituição. Como finalidades peculiares procurou-se entender os fundamentos da Administração Pública e delinear as metodologias, tecnologias e os recursos instituídos no controle patrimonial pelo ente Público. Desta forma, para aprofundar o conhecimento acerca do tema Gestão Patrimonial no setor público, esta pesquisa apresenta como objetivo geral analisar os procedimentos referentes à gestão patrimonial adotados pelo CIEP 293 - Walmir de Freitas Monteiro, com vistas ao desfazimento de bens inservíveis à luz do Decreto 9.373/18 e suas atualizações, e propor melhorias no processo em questão. Para tanto, utilizou-se uma pesquisa aplicada, com realização de entrevista com a diretora do Ciep para levantamento das informações. Os resultados demonstram que o CIEP 293 atende parcialmente ao que determina o Decreto 9.373/18 no que se refere ao tratamento dos bens inservíveis, devendo a mesma adotar medidas corretivas visando o bom andamento das atividades da Gestão Patrimonial da Instituição.

Palavras-chave: Gestão Patrimonial. Controle. Administração Pública.

ABSTRACT: The purpose of this article is to study the patrimonial control of assets in public administration as an instrument of Public Governance. Asset Management aimed at public administration has as its main objective to meet the demands for permanent and consumable materials in order to enable the various activities developed in a given institution. As peculiar purposes, an attempt was made to understand the fundamentals of Public Administration and to delineate the methodologies, technologies and resources instituted in patrimonial control by the Public entity. Thus, in order to deepen the knowledge on the topic of Asset Management in the public sector, this research has as a general objective to analyze the procedures related to asset management adopted by CIEP 293 - Walmir de Freitas Monteiro, with a view to undoing unserviceable assets in the light of the Decree 9,373/18 and its updates, and propose improvements to the process in question. For that, an applied research was used, with an

\footnotetext{
${ }^{1}$ Universidade Federal Fluminense Administração Pública-UFF .
} 
interview with the director of Ciep to gather the information. The results show that CIEP 293 partially meets the requirements of Decree 9,373/18 with regard to the treatment of unserviceable assets, and that it must adopt corrective measures aimed at the smooth running of the Institution's Asset Management activities.

Keyword: Asset Management. Control. Public Administration.

\section{INTRODUÇÃO}

O presente estudo, tem por intuito fazer uma análise sobre a gestão patrimonial na administração pública, visando evidenciar a importância de se realizar a administração patrimonial dos bens permanentes, por meio do emprego de ferramentas institucionais, de maneira que reflita a real disposição patrimonial física da instituição.

Para Barbosa (2015), a Gestão Patrimonial voltada a Administração Pública tem por objetivo principal atender às demandas por materiais permanentes e de consumo, com o intuito de viabilizar as diversas atividades desenvolvidas em um determinado Órgão Público, sem perder de vista o controle, a integridade e a acuracidade dos registros patrimoniais atendendo, assim, as exigências e normativos dos órgãos de controle, quer seja Interno como a Auditoria Interna, quer sejam externos como o Tribunal de Contas da União (TCU) e a Controladoria Geral da União (CGU).

Quando desempenhada corretamente, esta gestão assegura os benefícios especificamente ligados a qualquer planejamento de controle, assim como a prevenção das penalidades aplicadas aos gestores que deixam de cumprir o dever de zelar pelo patrimônio público.

O controle é feito com base em leis federais, estaduais e normas internas dos órgãos ou entidades, podendo ser interno e externo. As leis federais 8.666/93, 4.320/64 e LC 10I/200o, com as publicações das portarias do tesouro nacional, dispõem que o setor de patrimônio, encarregado do controle de bens do patrimônio público, deverá ser responsável por muito mais tarefas do que o simples controle físico dos bens e sua localização.

Com advento da Lei Ir.638/o7, CPC or e CPC 27, a gestão patrimonial não é apenas mais uma obrigação burocrática de controlar os bens do ativo imobilizado, torna-se 
responsabilidade da instituição assegurar a veracidade das informações sobre os ativos e a situação contábil da administração pública.

Assim, a gestão patrimonial permite controlar e gerar informações fundamentais sobre o ativo imobilizado, possibilitando saber qual é o patrimônio real, onde estão localizadas, as características principais, durabilidade, vida útil total e remanescente dos bens. Permite ainda o controle do sistema integrado de administração de pessoal, o registro de alterações cadastrais nos bens e a geração dos registros do SPED Fiscal.

O estudo tem por objeto o CIEP 293 - Walmir de Freitas Monteiro, localizado no município de Volta Redonda e tem por questionamento: diante das ferramentas e leis para controle do patrimônio público, ainda presenciamos sucateamento de ativos e o mau uso de bens públicos? Quais estratégias poderão ser adotadas, para melhor gestão do patrimônio público?

Desta forma, para aprofundar o conhecimento acerca do tema Gestão Patrimonial no setor público, esta pesquisa apresenta como objetivo geral analisar os procedimentos referentes à gestão patrimonial adotados pelo CIEP 293 - Walmir de Freitas Monteiro, com vistas ao desfazimento de bens inservíveis à luz do Decreto $9.373 / 18$ e suas atualizações e propor melhorias no processo em questão.

Já os objetivos específicos visam demonstrar, sob o aspecto do Decreto 9.373/18, de que forma os bens públicos inservíveis são tratados na gestão patrimonial do CIEP; identificar as não conformidades por ventura existentes na gestão patrimonial de bens inservíveis no âmbito da referida Instituição, tendo como base o Decreto 9.373/18 e, por fim, com amparo nos resultados da pesquisa, propor plano de melhorias para o setor responsável pela Gestão Patrimonial.

Por fim, a relevância deste trabalho encontra-se na busca por melhores práticas administrativas como forma de contribuir para o avanço da Administração Pública, sobretudo na gestão patrimonial, visando a otimização dos recursos disponíveis, confrontando os conhecimentos teóricos levantados em fontes bibliográficas à realidade encontrada no lócus da pesquisa, na busca por novos conhecimentos acerca do tema, com intuito de propiciar uma melhor aplicação dos dispositivos legais relacionados à gestão patrimonial no setor público. 


\section{CONCEITO DE PATRIMÔNIO PÚBLICO}

Em linhas gerais, Patrimônio Público nada mais é que o conjunto de bens e direitos, tangíveis ou intangíveis, onerados ou não, adquiridos, formados ou mantidos com recursos públicos, integrantes do patrimônio de qualquer entidade pública ou de uso comum, que seja portador ou represente um fluxo de benefícios futuros inerentes à prestação de serviços públicos (MELLO et al, 2015).

De acordo com Pierre (2000), bens públicos são todas as coisas materiais ou imateriais pertencentes às pessoas públicas e submetidas a um regime de Direito Público instituído em favor do interesse público.

Duarte Júnior (2006, p. 26) conceitua patrimônio consistindo "o conjunto de bens avaliados em dinheiro, relacionando-se simultaneamente às esferas da natureza, da genética, da economia, da nação e, também, como não poderia deixar de ser, à da cultura”.

Costa (2011, p. 28) abrange patrimônio como sendo: “a empresa do ser humano relacionado à tríade arte/memória coletiva/repasse de saberes, protegida pelo direito, tendo em vista o princípio constitucional da dignidade, tanto do universo humano, quanto dos indivíduos, ligada à ideia emancipatória de desenvolvimento".

O conceito se estende quando o patrimônio passa a ser imaterial, cultural, urbanístico, paisagístico, social e natural, ou seja, são múltiplos conceitos de patrimônio para que se possa entender sua riqueza como bem público, que deve ser usado com sustentabilidade e respeito, seja material ou imaterial (ELIAS, 1994).

O patrimônio público, para Torres e Silva (2003), é composto por bens de toda natureza e espécie, que tenham interesse para a administração pública e para a comunidade administrada, já Kohama (20oI, p. 213), define que patrimônio público é o conjunto de bens, direitos e obrigações, avaliados em moeda corrente, das entidades que compõem a administração pública.

\section{GESTÃO PATRIMONIAL NA ADMINISTRAÇÃO PÚBLICA}

A Gestão Patrimonial no setor público está relacionada ao ciclo de vida dos bens pertencentes a uma instituição, este ciclo inicia-se na aquisição do bem, em uma das suas diversas modalidades, passando pelo controle, conservação e findando-se com a baixa patrimonial. Diferentemente do que acontece no setor privado, todas essas atividades inerentes à 
gestão patrimonial no setor público são norteadas por força de Lei, com o objetivo de atender aos preceitos da Administração Pública.

Dornelles (2009) agrega a definição, como um conjunto de procedimentos, de métodos e de rotinas que têm, como principal foco, proteger o acervo patrimonial e agregar qualidade à gestão através de ações preventivas que compreendam planejamento e avaliação periódica da atuação administrativa, dentro da mais absoluta legalidade.

De acordo com Santos (2010), a administração patrimonial é composta por uma sequência de atos administrativos que envolvem vários procedimentos, desde a aquisição, geralmente ocorrido no setor de compras, até a sua exclusão do patrimônio da instituição. Desta forma podemos compreender a Administração Patrimonial como o conjunto de medidas adotadas com vistas à manutenção da integridade e acuracidade dos registros referentes aos bens pertencentes a um órgão público (COUTINHO, 2005).

Os bens patrimoniais no contexto contábil/administrativo são classificados em tangíveis e intangíveis. Os bens tangíveis ou corpóreos, como o nome sugere, têm forma, como por exemplo equipamentos de laboratórios, mobiliários em geral, computadores e veículos, enquanto os bens intangíveis ou incorpóreos não possuem forma física, como as marcas, patentes, logotipos e licença de utilização de software, entre outros (MOTA, 2009). Quanto aos bens tangíveis podemos classificá-los em bens móveis e bens imóveis. Os bens imóveis são estáticos e não podem ser movimentados sem prejudicar sua integridade física, como os prédios, terrenos e edificações em geral, já os bens móveis podem ser distinguidos entre bens de consumo e bens permanentes (MOTA, 2009). De acordo com a portaria 448, da Secretaria do Tesouro Nacional (STN) de 13 de setembro de 2002, art. 2º, inciso II, Material Permanente está conceituado como aquele que, em razão do seu uso corrente, não perde a sua identidade física, mesmo quando incorporado a outro bem, tendo ainda como requisito básico uma durabilidade superior a dois anos (BRASIL, 2008).

Diante da determinação constitucional e de elementos contextuais que a precederam ou favoreceram, ocorreu uma evolução das concepções de controle no Brasil, acompanhada de alterações nas suas estruturas. Nos contextos histórico e institucional o controle interno do Poder Executivo da União passa por uma transformação que, de forma muito superficial, poderia ser resumida como uma mudança de concepção de controle legalista e procedimental, 
para um controle voltado à avaliação das políticas públicas, combate à corrupção e, posteriormente, fomento ao controle social. Tal mudança conceitual é acompanhada pela mudança organizacional, com a extinção do frágil modelo de Secretarias de Controle Interno (denominadas à época pela sigla CISETs) e surgimento de uma nova instituição em 2003, a Controladoria Geral da União(CGU), em alteração à denominação anterior de Corregedoria Geral da União (PEREIRA; DANTAS; AZEVEDO, 2015).

Implementar uma gestão patrimonial eficaz e atuante em cada instituição é fundamental para atender as exigências impostas pelos órgãos de controle da Administração Pública, uma vez que os mesmos atuam como fiscais da aplicação de recursos oriundos dos cofres públicos e realizam verificações periódicas visando coibir e corrigir eventuais desvios. $\mathrm{Na}$ opinião de Coutinho (2005), manter a acuracidade dos registros patrimoniais, bem como promover periodicamente baixas dos bens que não reúnem mais as condições de uso desejáveis, deve ser uma constate na rotina do setor de gestão patrimonial. A correta utilização, bem como os cuidados no uso dos equipamentos são determinantes para a vida útil dos bens permanentes de uma instituição. Quanto maiores forem os cuidados empregados, menores serão as necessidades de manutenção corretiva e consequentemente maior seu tempo de utilização, prolongando assim a vida útil dos bens patrimoniais. Para Bernardes (2008), a gestão patrimonial engloba vários aspectos e procedimentos indispensáveis à preservação do patrimônio público, contudo, atentar-se para as peculiaridades inerentes aos procedimentos de desfazimento de bens é de fundamental importância para a manutenção da fidedignidade dos registros contábeis e patrimoniais das instituições públicas.

A Constituição Cidadã em seu artigo 74 indica que cada poder deverá possuir o seu sistema de controle interno, sendo que seus responsáveis possuem responsabilidade solidária na presença de qualquer desvio, respondendo civil ou penalmente (BRASIL,1988). O controle interno deverá ter por atribuições:

I - avaliar o cumprimento das metas previstas no plano plurianual, a execução dos programas de governo e dos orçamentos da União;

II - comprovar a legalidade e avaliar os resultados, quanto à eficácia e eficiência, da gestão orçamentária, financeira e patrimonial nos órgãos e entidades da administração federal, bem como da aplicação de recursos públicos por entidades de direito privado; 
III - exercer o controle das operações de crédito, avais e garantias, bem como dos direitos e haveres da União;

IV - apoiar o controle externo no exercício de sua missão institucional. (BRASIL, I988).

Para Bernardes (2008, p.22), "o controle interno encontra fundamento no Art. 74 da Constituição Federal, o qual determina que os Poderes Executivo, Legislativo e Judiciário devem manter, de forma integrada, sistemas de controle interno". O controle interno serve para controlar a conclusão orçamental patrimonial, ativo financeiro e contábil das instituições, objetivando a consonância com as legislações e a harmonia das contas públicas, que necessitam primar nos órgãos públicos, formando prerrogativa ao exame real de direções públicas do País.

Com o advento da Lei de Responsabilidade Fiscal o legislador percebeu a necessidade de uma lei que regulasse a gestão sobre o patrimônio público e resolveu dedicar um capítulo integral sobre esse tema. Através da aprovação e posterior publicação, o processo de administração financeira, orçamentária, patrimonial e contábil operado pela União e pelos Estados brasileiros, que logo demonstraram sua precaução com o patrimônio público, requisitou dos órgãos da administração direta e indireta uma explicação melhor da destinação dos bens da administração pública.

\section{I PROCEDIMENTOS DE CONTROLE PATRIMONIAL}

Os bens patrimoniais, devido à utilização e pela deterioração proveniente do tempo, sofrem diminuição do correspondente valor real que se intitula depreciação, podendo ser ocasionada por corrosões, por perda de utilidade, por uso, por atos da natureza ou por redução da vida útil.

No cálculo da depreciação é realizado um estudo na divisão do valor contábil pelo período de vida útil do patrimônio, analisando a introdução no valor contábil e no valor da conta de depreciação e os valores oriundos de reavaliações, conforme a obediência do artigo I48, inciso $\mathrm{V}$ da Lei Federal n ${ }^{\circ}$ 4.320/64 (BRASIL, 1964).

O art. 183 da Lei $\mathrm{n}^{\mathrm{o}}$ 6.404/76 estabelece, em seu $2^{\circ}$ :

A diminuição de valor dos elementos do ativo imobilizado será registrada periodicamente nas contas de: 
Depreciação, quando corresponder à perda de valor dos direitos que têm por objeto os bens físicos a desgastes ou perda de utilidade por uso, ação da natureza ou obsolescência.

Este processo deve ser realizado todos os anos pelas entidades, alterando o valor de toda unidade do patrimônio para integrar o inventário anual. O valor do bem depreciado acumulado, conforme sujeitada à revisão monetária, de modo nenhum pode transcender o valor do preço do bem e a devida correção monetária.

No contexto atual, os organismos de controle da Administração Pública desenvolvem, sobretudo, o papel de fiscalização da aplicação de normas, regimentos e principalmente de recursos originários dos cofres públicos (BERNARDES, 2008). Nesse sentido os principais órgãos de controle a quem a gestão patrimonial, no âmbito de instituições públicas da União se subordinam, são a Controladoria-Geral da União (CGU) e o Tribunal de Contas da União (TCU), que atuam como agentes de controle externos, e a Auditoria Interna que, como o próprio nome indica, age de forma interna, como instância fiscalizadora das ações desenvolvidas em cada organização. A Controladoria-Geral da União (CGU) é o órgão do Governo Federal responsável por assistir direta e imediatamente ao Presidente da República quanto aos assuntos que, no âmbito do Poder Executivo, sejam relativos à defesa do patrimônio público e ao incremento da transparência da gestão, por meio das atividades de controle interno, auditoria pública, correição, prevenção e combate à corrupção e ouvidoria. A CGU também deve exercer, como órgão central, a supervisão técnica dos órgãos que compõem o Sistema de Controle Interno e o Sistema de Correição e das unidades de ouvidoria do Poder Executivo Federal, prestando a orientação normativa necessária (PEREIRA; DANTAS; AZEVEDO, 2015). No entanto, o órgão que atua de forma mais direta na fiscalização dos atos da gestão patrimonial é a auditoria interna, isso se dá por conta do caráter autônomo no que se refere à gestão administrativa e financeira exercida em cada instituição, ou seja, decorre do seu próprio poder de autotutela, permitindo à Administração Pública rever os seus próprios atos, casos ilegais, inoportunos ou inconvenientes, sempre com fulcro nos princípios da legalidade, supremacia do interesse público, eficácia e economicidade (SANTANA, 2014).

Os bens da administração pública devem passar pelo inventário periodicamente, ou seja, tem que possuir uma relação atualizada do patrimônio. A Administração pública é obrigada encontrar o valor justo, isto é, o valor de mercado desses bens que estão inventariados. 
De acordo com a Portaria no 350 , de 29 de Junho de 2020, outra obrigação importante é avaliação dos bens móveis e imóveis, podendo ser de dois tipos. O primeiro é a reavaliação, ou seja, o valor contábil na peça do balanço patrimonial está defasado, então tem a necessidade de se fazer uma estimativa maior, reavaliar, ficando o balanço patrimonial com mais crédito, gerando uma variação patrimonial aumentativa, ao contrário se faz o implement, ou seja, o valor contábil está a maior no balanço, então deve-se diminuir, fazendo um lançamento numa VPD (Variação Patrimonial Diminutiva) (BRASIL, 2020).

Ainda segundo a referida Portaria, outro tipo de avaliação é a realização do lançamento da depreciação, amortização ou exaustão, que consiste em fazer a contabilização do consumo do bem móvel ou imóvel no decorrer dos períodos mensais, é a depreciação até o momento da avaliação, para que se tenha o valor final justo daquele bem e que será a contabilização final escriturada no balanço patrimonial (BRASIL, 2020).

A Portaria ainda sustenta que no tangente à reavaliação, a técnica de atualização dos valores dos bens de uma entidade é através da análise do custo do negócio, embasada em opiniões técnicas, mediante pareceres em que a diversidade entre o valor original constante e o valor reexaminado deve ser anotada no patrimônio (BRASIL, 2020).

A Lei 4.320/64 concede que se aja à reavaliação dos bens móveis e imóveis, processo este que, disposto devidamente, torna mais objetivo o valor do bem público. No decorrer da composição dos inventários, uma das ações importantes é a análise dos elementos integrantes do patrimônio, que se faz pelo valor de obtenção de constituição ou de rendimento para os bens móveis e imóveis ou de provisões industriais, ressaltando que, depois da publicação da lei que estabeleceu normas de direito financeiro para elaboração e controle dos orçamentos e balanços, a reavaliação tornou-se obrigatória (BRASIL, 1964).

\section{METODOLOGIA}

A área de estudo desta pesquisa refere-se à Coordenação de Patrimônio do CIEP 293 - Walmir de Freitas Monteiro. Para a realização desta pesquisa fez-se necessário um levantamento prévio dos normativos que regem a Gestão Patrimonial no setor público, bem como uma busca por bibliografia relacionada ao assunto, visando à apropriação de conceitos e conhecimentos acerca do tema proposto. Esta pesquisa classifica-se como aplicada e descritiva, uma vez que o pesquisador buscou uma maior proximidade com o fenômeno pesquisado, e 
utilizou-se a ferramenta de estudo de caso, visando descrevê-los em seus pormenores, atendendo a critérios qualitativos, que tem como propósito principal analisar atitudes, comportamentos, hábitos e tendências dos fatos investigados (BARBOSA, 2015).

Quanto à pesquisa descritiva, Gil (2010) se posiciona afirmando que esta tem como importante objetivo descrever as características de determinada população ou fenômeno, envolvendo técnicas padrão de coleta de dados, como questionários e observação sistemática. Utilizou-se como instrumento de coleta de dados o modelo de entrevista semiestruturada, que foi gravada através de recursos audiovisuais, visando um melhor aproveitamento das informações coletadas. De acordo com MOURA (1998, p. 78), este tipo de entrevista se apresenta sob a "forma de um roteiro preliminar de perguntas, que se molda à situação concreta de entrevista, tendo o entrevistador liberdade de acrescentar novas perguntas a esse roteiro". O estudo foi realizado entre os meses de julho e agosto de 202I, utilizando como principais fontes de informações a entrevista realizada com a pessoa responsável pelo Material e Patrimônio da instituição, no que se refere aos procedimentos referentes à gestão patrimonial adotados pelo CIEP 293 - Walmir de Freitas Monteiro, à luz do Decreto 9.373/18, que dispõe sobre a alienação, a cessão, a transferência, a destinação e a disposição final ambientalmente adequadas de bens móveis no âmbito da administração pública federal direta, autárquica e fundacional, bem como análise documental realizada In-loco, nos arquivos da unidade gestora do patrimônio e em sistema computacional de controle patrimonial disponível na referida instituição.

A estruturação do roteiro para a entrevista possibilitou o desenvolvimento de um diálogo capaz de levantar pontos relevantes quanto aos procedimentos relacionados à destinação dos bens pertencentes ao CIEP 293 - Walmir de Freitas Monteiro, que não apresentam condições de utilização, passando a ser classificados como inservíveis. Desta forma, foi possível aprofundar conhecimentos sobre os seguintes pontos:

- Aplicabilidade dos dispositivos legais que regem o desfazimento de bens no setor público;

- Planejamento e execução de programas de conservação e manutenção de bens permanentes; 
- Peculiaridades inerentes ao reaproveitamento de bens permanentes na administração Pública.

A partir das informações coletadas foi possível realizar uma análise com enfoque qualitativo, norteada pelos objetivos geral e específicos propostos na elaboração da pesquisa. Para Vergara, (2000, p. 16), "a coleta, através de diversas fontes, tem como objetivo permitir a triangulação dos dados coletados, a fim de se abranger a máxima amplitude no momento da descrição, explicação e compreensão do foco em estudo”. Desta forma foram levantados aos resultados que são apresentados e discutidos a seguir.

\section{ANÁLISE E DISCUSSÃO DOS DADOS}

O CIEP 293 - Walmir de Freitas Monteiro foi inaugurado em 13/07/2009 e após 12 anos conta com 20 servidores públicos em seu quadro funcional distribuídos pelos diversos setores do CIEP. Deste quantitativo de servidores, 02 (Secretária e Diretora) atuam diretamente na gestão de materiais - bens de consumo e bens permanentes, sendo responsáveis pela Gestão do Almoxarifado, Manutenção de Bens Móveis e Patrimônio Imobiliário.

Após a realização do estudo que buscou analisar de que forma são tratados os bens móveis considerados inservíveis pela Gestão patrimonial do CIEP 293, tendo como base os preceitos norteadores contidos no Decreto 9.373/18, foi possível chegar aos seguintes resultados.

\section{I QUANTO AO CONTROLE DE BENS MÓVEIS NO CIEP 293}

De acordo com os arquivos do CIEP 293, a escola tem registrado no seu acervo patrimonial 940 bens permanentes distribuídos em vários grupos de classificação. Deste total 45I, ou seja, 48\% possuem entre cinco e dez anos de utilização. Ainda de acordo com os arquivos, do total de bens cadastrados, I3I itens ou 13,94\% são classificados como equipamento de processamento de dados, e outros 529 itens, o que corresponde a $56,37 \%$, estão cadastrados como mobiliário em geral.

Não foi possível mensurar quantidade exata de bens inservíveis no CIEP 293, uma vez que será realizada a análise de bens considerados antieconômicos, ou seja, bens cuja manutenção seja considerada onerosa, ou seu rendimento precário, em virtude de uso prolongado, desgaste prematuro ou obsoletismo, ou cujo custo de recuperação ultrapasse 50\%, conforme prevê o 
subitem 9.3 da IN SEDAP 205 de 1988. Com relação aos bens danificados, a recuperação somente será considerada viável se a despesa envolvida com o bem móvel orçar no máximo a 50\% (cinquenta por cento) do seu valor estimado no mercado. Caso seja considerado antieconômico ou irrecuperável, o material será alienado, em conformidade com o disposto na legislação vigente.

A referida IN determina ainda que os bens que se encontrem nessa situação sejam doados, mediante autorização da Autoridade Competente, para os Estados e Municípios mais carentes, Distrito Federal, empresas públicas, sociedades de economia mista e instituições filantrópicas, reconhecidas de utilidade pública pelo Governo Federal.

Diante do exposto, se faz necessário a aplicação do sistema de controle de bens em manutenção, uma vez que o acompanhamento da vida útil dos bens permanentes do CIEP 293 não existe. Como forma de minimizar os gastos com a manutenção, indica-se a criação de campanha institucional visando à preservação e controle dos bens patrimoniais da Instituição.

Sugere-se também que seja implementado um plano de metas formal, no qual seja contemplado um planejamento detalhado das atividades do setor, no que se refere ao planejamento de aquisições de bens, haja vista a previsão de aumento do número de bens que atingiram a condição de inservível, levando-se em conta a idade média dos bens móveis permanentes do CIEP 293 - as informações referentes a média de idade dos bens pertencentes a Unidade Escolar indicam uma alta concentração em grupos que apresentam curta vida útil como mobiliários e equipamentos de informática. Também sugere-se que seja contemplado, no referido plano de metas, medidas no tocante ao desfazimento de bens inservíveis com objetivo de nortear as ações da Gestão Patrimonial em médio prazo.

\subsection{QUANTO AO TRATAMENTO DE BENS INSERVÍVEIS DA INSTITUIÇÃO}

De acordo com a Diretora Ana Claudia Calhau Poell, ao constatar bens inservíveis, a Unidade Escolar monta um processo para descarte e encaminha para a Secretaria de Estado de Educação, que analisará as informações e dará o parecer para a Instituição Pública realizar o descarte dos materiais. Cumpre salientar que o processo fica arquivado junto a Secretaria Estadual de Educação, disponível para consulta em caso de necessidade. 
Perguntada a respeito da realização de processos formais de desfazimento, a Diretora informou que durante a Gestão atual foram efetuados dois processos de desfazimento de bens, onde foi contratada uma empresa cadastrada na base Estadual para descarte dos bens inservíveis. Ainda de acordo com a gestora, até o momento não foi realizado nenhum leilão ou doação referente aos demais tipos de bens.

Questionada sobre o acompanhamento da vida útil dos bens permanentes da Instituição, a Diretora afirma que não existe uma análise periódica através de relatórios de bens em manutenção nos quais, segundo ela, os bens que apresentam menor vida útil são os de informática, seguidos por mobiliários em geral e equipamentos energéticos (no-breaks e estabilizadores).

Quanto aos bens de informática, não foram verificados envios de informação mediante ofício ou meio eletrônico à Secretaria de Logística e Tecnologia da Informação sobre a existência de microcomputadores de mesa, monitores de vídeo, impressoras e demais equipamentos de informática, respectivo mobiliário, peças-parte ou componentes, classificados como ocioso, recuperável, antieconômico ou irrecuperável, disponíveis para reaproveitamento. Aconselha-se que seja feito o envio de informações atualizadas à Secretaria de Logística e Tecnologia da Informação a respeito dos bens de informática disponíveis para desfazimento visto que estes configuram a maior parte dos bens inservíveis armazenados aguardando destinação. Com isto, espera-se instrumentalizar um estudo de viabilidade de doação dos referidos bens a instituições filantrópicas que possam, de alguma maneira, utilizá-los em suas atividades. Tal medida possibilitaria a redução do número de bens inservíveis na Instituição e representaria um aprimoramento da utilização do Decreto 9.373/ı no CIEP 293 - Walmir de Freitas Monteiro.

\subsection{QUANTO AO REAPROVEITAMENTO DE BENS INSERVÍVEIS}

O decreto 9.373/18 autoriza no Parágrafo Único o reaproveitamento de bens ao determinar que "Verificada a impossibilidade ou a inconveniência da alienação do bem classificado como irrecuperável, a autoridade competente determinará sua destinação ou disposição final ambientalmente adequada, nos termos da Lei no $12.305 /$ Io". 
Contudo, por informação da Diretora, foi constatado que nunca houve reaproveitamento de bens inservíveis no CIEP 293 - Walmir de Freitas Monteiro, sendo sugerido a abertura de processo formal de reaproveitamento de peças economicamente viáveis e a criação de um cadastro de peças que deverão ser incorporadas aos bens, em substituição a componentes danificados, sendo efetuado o devido registro patrimonial conforme prevê o normativo em questão.

Por fim, indica-se também que seja efetuada atualização dos dados dos bens inservíveis, com o intuito de instruir a abertura de novos processos de alienação de bens, com vistas a redução do custo de armazenagem de bens que já não são mais utilizados pela Instituição.

\section{CONCLUSÃO}

Norteada pelo objetivo geral de analisar os procedimentos referentes à gestão patrimonial adotados pelo CIEP 293 - Walmir de Freitas Monteiro, com vistas ao desfazimento de bens inservíveis à luz do Decreto 9.373/18 e suas atualizações, bem como propor melhorias

neste processo, a presente pesquisa diagnosticou que que a Diretoria e Secretaria já aplicam de forma parcial as exigências previstas no Decreto 9.373/18 no que se refere aos bens inservíveis, contudo, é necessário que sejam envidados esforços no sentido de potencializar a eficácia das ações.

Em relação aos bens inservíveis, foi constatado grande potencial para reaproveitamento de peças viáveis, evitando descartar o bem por completo, cadastrando as peças que passariam a compor o bem em questão, conforme prevê o referido Decreto. Também é necessário atualização constante da lista de bens inservíveis para evitar custos com armazenagem de bens que não são mais utilizados pela instituição. Por último e não menos importante, é aconselhável viabilizar a doação de equipamentos de informática, uma vez que representam a maior parte dos bens inservíveis. Tal medida poderia ser realizada através do envio de informações atualizadas à Secretaria de Logística e Tecnologia da Informação a respeito dos bens de informática disponíveis para desfazimento.

Para aquisição de bens, sugere-se um planejamento levando em conta a quantidade de bens que se tornaram inservíveis, de acordo com a idade média pré-estabelecida. Também se faz 
necessário a aplicação do sistema de controle de bens em manutenção uma vez que o acompanhamento da vida útil dos bens permanentes do CIEP 293 não existe. Como forma de minimizar os gastos com a manutenção indica-se a criação de campanha institucional visando à preservação e controle dos bens patrimoniais da Instituição.

Como limitação da pesquisa, pode-se citar a reduzida amostra de processos consolidados no CIEP 293 - Walmir de Freitas Monteiro, o que impacta na não possibilidade de maior aprofundamento da pesquisa.

Por fim, cabe salientar que apesar de ter alcançado os objetivos propostos na elaboração da pesquisa, este estudo não teve a pretensão de esgotar o tema em questão, motivo pelo qual sugere-se a realização de novos esforços investigativos visando o aprofundamento dos conhecimentos a respeito da temática, bem como a melhoria dos processos inerentes a Gestão Patrimonial no setor público.

\section{REFERÊNCIAS}

BANDEIRA DE MELlO, Celso Antônio. Curso de Direito Administrativo. São Paulo: Malheiros, 18 ed., 2005.

BERNADES, José Francisco. Administração patrimonial. Florianópolis: IU/UFSC, 2011. $272 \mathrm{p}$.

BRASIL. Constituição (1988). Constituição da República Federativa do Brasil. Brasília: Senado Federal, Centro Gráfico, 1988.

BRASIL, Lei n. 10.406, de ro de janeiro de 2002. Institui o Código Civil Diário Oficial [da] República Federativa do Brasil, Brasília, DF, il jan. 2002. Disponível em: < http://www.planalto.gov.br/ccivil_03/leis/lcp/lcpior.htm>. Acesso em: I8/o2/202I

BRASIL. Lei Complementar n. Ior, de 4 de maio de 2000. Estabelece normas de finanças públicas voltadas para a responsabilidade na gestão fiscal e dá outras providências. Diário Oficial [da] República Federativa do Brasil, Brasília, DF, 05 maio. 200o. Disponível em: 〈http://www.planalto.gov.br/ccivil_03/leis/lcp/lcpior.htm>. Acesso em: 13/03/2021

BRASIL. Lei n. 4.320, de 17 de março de 1964 - Estatui Normas Gerais de Direito Financeiro para elaboração e controle dos orçamentos e balanços da União, dos Estados, dos Municípios e do Distrito Federal. Diário Oficial [da] República Federativa do Brasil, Brasília, DF, 04 maio. 1964. 

$17 / 03 / 2021$

Disponível em: 〈http://www.planalto.gov.br/ccivil_03/leis/1432o.htm〉. Acesso em:

BRASIL. Lei n. 8.666, de 2i de junho de 1993 - Regulamenta o art. 37, inciso XXI, da Constituição Federal, institui normas para licitações e contratos da Administração Pública e dá outras providências. Diário Oficial [da] República Federativa do Brasil, Brasília, DF, 22 jun. 1993. Disponível em: 〈http://www.planalto.gov.br/ccivil_03/leis/18666cons.htm〉. Acesso em: 15/05/2021

BRASIL. Lei n. Ir.638, de 28 dezembro de 2007. Altera e revoga dispositivos da Lei n. 6.404, de 15 de dezembro de 1976, e da Lei n. 6.385, de 7 de dezembro de 1976, e estende às sociedades de grande porte disposições relativas à elaboração e divulgação de demonstrações financeiras. Diário Oficial [da] República Federativa do Brasil, Brasília, DF, 28 dez. 2007.

Disponível em: 〈http://www.planalto.gov.br/ccivil_03/_ato20072010/2007/lei/lir638.htm>. Acesso em: 17/05/2021

BRASIL. Portaria no 350 , de 29 de Junho de 2020. Altera e revoga dispositivos do art. $5 \mathrm{I}$ da Lei Complementar n. Ior, de 04 de Maio de 200o, e estende às sociedades de grande porte disposições relativas à elaboração e divulgação de demonstrações financeiras. Diário Oficial da União, Brasília, DF, 30 jun. 2020.

Disponível em: < https://www.in.gov.br/en/web/dou/-/portaria-n-35o-de-29-de-junhode-2020-264173521>. Acesso em: 17/05/2021

BRASIL. Superior Tribunal de Justiça. Revista Eletrônica de Jurisprudência. Súmula n. 340, DJe 13/12/1963. Ementa: "Desde a vigência do Código Civil, os bens dominicais, como os demais bens públicos, não podem ser adquiridos por usucapião.”. Disponível em: <www.stf.jus.br> Acesso em: 30/05/2021

BRASIL. Tribunal de Justiça de Santa Catarina. Diário da Justiça Eletrônico. Apelação Cível: 0312358.93.2015.8.24.0020. Relator: Jaime Ramos. Terceira Câmara de Direito Público, DJe 14/o5/2019. Disponível em www.tjsc.jus.br Acesso em: 31/o5/2021

CARVALHO FILHO, José dos Santos. Manual de direito administrativo. 27. ed. São Paulo: Atlas, 2013

COSTA, Rodrigo Vieira. A dimensão constitucional do patrimônio cultural: o tombamento e o registro sob a ótica dos direitos culturais. Rio de Janeiro: Lumen Juris, 20II.

COUTINHO, José Roberto de Coutinho (Ed.) et al. Gestão Patrimonial na Administração Pública. Editora Lumen Juris: Rio de Janeiro, 2005, 407 p.

DORNElles, G. M. R. Controle interno na Administração Pública. Porto alegre. 2009. Trabalho de conclusão Gestão Pública. 
DUARTE JÚNIOR, Romeu. Produção arquitetônica, cultura e patrimônio: a arquitetura cearense. Aspectos: Revista do Conselho Estadual da Cultura e do Conselho Estadual de Preservação do Patrimônio Cultural do Estado do Ceará, Fortaleza, v. 25, p. 26-35, 2006.

ELIAS, Norbert. O processo civilizador. Rio de Janeiro: Jorge Zahar, I994. v. I

GIL, Antônio Carlos. Métodos e técnicas de pesquisa social. 6. ed. São Paulo: Atlas, 2010.

LOPES, Miguel de Serpa. Curso de direito civil. 8. ed. Rio de Janeiro: Freitas Bastos, 1996, v. 8.

MASCARENHAS BISNETO, José Pereira; FRAGA, Igor Dantas; BORGES, Siméa Azevedo Brito. Controle Interno do Poder Executivo Federal e o Estado da Bahia. Revista SulAmericana de Ciência Política, v. 3, n. I, I46-I68. Disponível em: 〈https://periodicos.ufpel.edu.br/ojs2/index.php/rsulacp/article/view/4666/4327〉. Acesso em 20 set. 2015. ed.,Brasília, 2009.

MOTA, Francisco Glauber Lima. Contabilidade aplicada ao setor público. I ${ }^{\underline{a}}$

MOURA, Maria Lucia Seidl de; FERREIRA, Maria Cristina; PAINE, Patricia Ann. Manual de elaboração de projetos de pesquisa. Rio de Janeiro: Ed. UERJ, 1998.

KOHAMA, H. Balanços Públicos: teoria e prática. 2ª ed. São Paulo: Atlas, 2000.

SILVA, Wesmey. Contabilidade Patrimonial no Setor Público

TORRES, F. Jr; SILVA, L. M. A importância do controle contábil e extra contábil dos bens permanentes adquiridos pela Administração Pública Federal. Revista de Contabilidade do Mestrado em Ciências Contábeis da UERJ, v.8, n.2, 2003. 